\title{
COVID-19, guests and crews of cruise: observation on Thai citizens
}

\author{
Sora Yasri ${ }^{1} \oplus$, Viroj Wiwanitkit ${ }^{2,3}$ \\ ${ }^{1}$ KMT Primary Care Centre, Bangkok, Thailand \\ ${ }^{2}$ Dr DY Patil University, Pune, India (honorary professor) \\ ${ }^{3}$ Hainan Medical University, Haikou, China (visiting professor)
}

COVID-19 is a new emerging infection starting from China [1]. This new disease was imported to many countries such as Thailand [2]. After the firs importation to Thailand as the first country, there are already more than 20 countries with imported disease. At first, the importation of disease is mainly by air travel. However, the new consideration is raised when there is an emerging problem of disease outbreak at international tourist cruise. The outbreak on Diamond Princess, which was detected in Japan, became an interesting situation.

Here, the authors would like to discuss on the observations on Thai citizens on that cruise. Based on available data, there 2 Thai guests and 23 Thai crews. From 3700 people on the cruise, there were 25 Thais and 3 of those
Thais (1 guest, 2 crews) got infection. The rate of infection among Thai citizens on the cruise is equal to $12 \%$ (95\% confidence interval [Cl]: 4.15-34.69\%). The infection rate among Thai guests and crews are 50\% (95\% Cl: 12.5-100\%) and $8.7 \%$ (95\% Cl: 2.31-32.69\%), respectively. Based on this observation, the infection rate among Thai guests is higher than that of Thai crews. It might reflect that the guest of the tourist cruise has a higher chance than crew to get disease in case of outbreak of new infection.

\section{REFERENCES}

1. Hsia W. Emerging new coronavirus infection in Wuhan, China: Situation in early 2020. Case Study Case Rep. 2020; 10(1): 8-9.

2. Yasri S, Wiwanitkit V. Editorial: Wuhan coronavirus outbreak and imported case. Adv Trop Med Pub Health Int. 2020; 10(1): 1-2. 